О. В. Еременко. К вопросу об эффективности инноваций в отдельных секторах деятельности нефтегазодобывающих предприятий

УДК $330 ; 338 ; 659 ; 658$

DOI: $10.18101 / 2304-4446-2018-1-33-43$

\title{
К ВОПРОСУ ОБ ЭФФЕКТИВНОСТИ ИННОВАЦИЙ В ОТДЕЛЬНЫХ СЕКТОРАХ ДЕЯТЕЛЬНОСТИ НЕФТЕГАЗОДОБЫВАЮЩИХ ПРЕДПРИЯТИЙ С ТОЧКИ ЗРЕНИЯ ВЛИЯНИЯ НА СЕБЕСТОИМОСТЬ ПРОДУКЦИИ
}

\author{
(C) Еременко Ольга Владимировна \\ кандидат экономических наук, \\ РГУ нефти и газа (НИУ) имени И. М. Губкина, филиал в г. Оренбурге \\ Россия, 460047, г. Оренбург, ул. Юных ленинцев, д. 20 \\ E-mail: overemenko71@mail.ru
}

В условиях ухудшения общемировой конъюнктуры рынка углеводородного сырья, технических проблем разработки и эксплуатации месторождений со значительной степенью выработанности, отсутствия источников финансирования рационального и адекватного мировому уровню технологий воспроизводства основных фондов, возрастания степени информатизации технологических процессов объективной становится необходимость внедрения инноваций в различных сфеpax деятельности нефтегазодобывающих предприятий. Однако вопросы оценки эффективности и установления приоритетности тех или иных нововведений наталкиваются на ряд особенностей, связанных со спецификой не только конкретных месторождений, но и секторов деятельности российских недропользователей. В статье представлены варианты унификации подходов к оценке инноваций с точки зрения влияния на снижение себестоимости продукции. С этой целью в работе применялись методы группировки и корреляционного-регрессионного анализа. Сформулированные предложения адаптированы на примере конкретного нефтегазодобывающего предприятия и могут быть использованы для определения эффективности энергосберегающих новшеств на объектах добычи углеводородного сырья.

Ключевые слова: инновации российских недропользователей; эффективность ресурсосберегающих нововведений.

Ослабление экономики нефтегазового сегмента российской экономики обусловлено ухудшающейся динамикой как макроэкономических [2], так и микроэкономических факторов, среди которых необходимо выделить: рост обводненности действующего фонда скважин; доли месторождений с трудноизвлекаемыми запасами и худшими фильтрационно-емкостными свойствами коллекторов; отсутствие в первоначальных геологических моделях разработки всех особенностей месторождений и, следовательно, технологий, позволяющих наиболее эффективно эксплуатировать их в связи с отсутствием таковых в период формулировки модели и т. д. [9]. Все эти обстоятельства ведут к увеличению себестоимости продукции и являются причинами перехода нефтегазового комплекса к инновационной модели развития. Актуальность рассматриваемого вопроса связана с тем, что в условиях недостатка инвестиционных ресурсов для организации комплексной инновационной дея- 
тельности возникает вопрос выбора наиболее эффективного технически-, финансово- и организационно-реализуемого варианта направления вложений [13]. При этом мы должны быть убеждены, что оценка эффективности произведена с учетом специфики месторождений, уровня производственного потенциала, а также влияния на показатели затрат предприятия.

При детальном изучении методик определения показателей эффективности инноваций мы пришли к выводу, что унифицированность расчетов, с одной стороны, позволяет сравнить нововведения в различных секторах деятельности недропользователей по системе универсальных показателей (ЧДД, ВНР, период окупаемости), с другой - не учитывает специфику производственных процессов и рисков внутри каждого сектора (добыча, переработка, транспорт, услуги собственного производства), потенциала сокращения затрат $[4 ; 6]$. Отсутствие классификации инноваций в разрезе этих критериев приводит к искажению оценки их результативности, как по эффективности и возможности их внедрения при сложившихся финансово-технологических условиях и минимальном риске, так и по степени влияния их на снижение себестоимости продукции.

Изучив себестоимость продукции (работ, услуг) в различных секторах деятельности ООО «Газпром добыча Оренбург» (рис. 1), мы можем утверждать, что в структуре регулируемых затрат наибольшую долю имеют материальные затраты. Так, в переработке они занимают 58\% [5], в магистральном транспорте - 57\%, в добыче - $11 \%$ (но если исключить НДПИ, доля материальных затрат составит 54\%), это говорит о приоритетности инноваций в ресурсосбережении [8].

Особенность затрат регионального нефтегазодобывающего предприятия заключается в том, что в части материальных затрат по технологическим процессам учитываются объекты управления:

- в рамках гелиевого и газоперерабатывающего заводов (сектор переработки) - сырой газ; химреагенты, катализаторы и другие вспомогательные материалы; запчасти на производственно-эксплуатационные нужды; газ на собственные технологические нужды; энергоресурсы; ГСМ [10];

- в газопромысловом управлении (сектор добычи и подготовки газа, нефти и конденсата) - только вспомогательные материалы: химреагенты и катализаторы (на добычу углеводородного сырья (УВС);

- в управлении по эксплуатации соединительных продуктопроводов (сектор транспортировки) - газ на собственные технологические нужды; энергия покупная; вспомогательные материалы на компримирование и распределение газа через газораспределительные станции;

- во вспомогательных подразделениях (сектор услуг собственного производства) - основные и вспомогательные материалы, запчасти, топливо и ГСМ, энергия. 
О. В. Еременко. К вопросу об эффективности инноваций в отдельных секторах деятельности нефтегазодобывающих предприятий

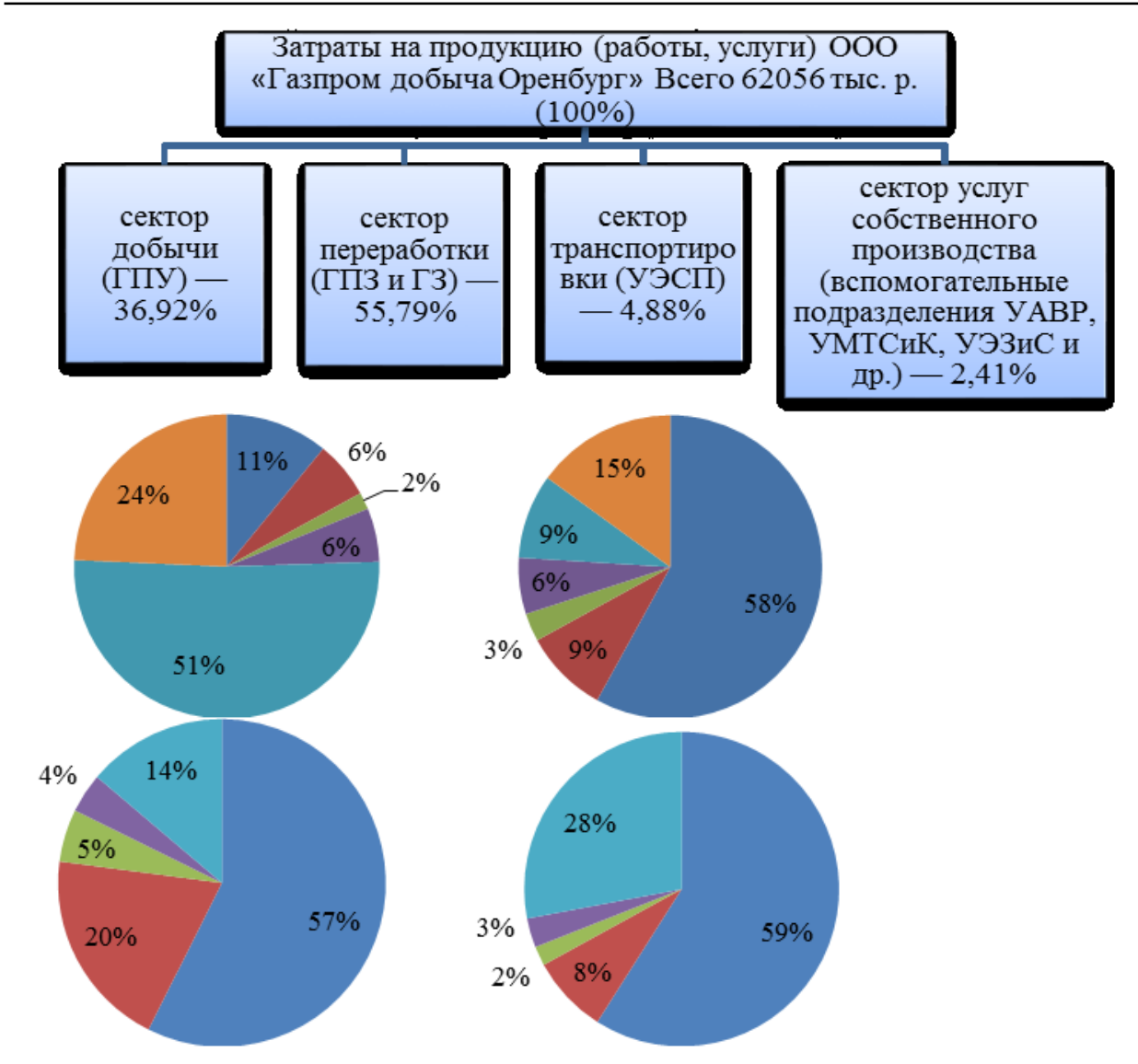

Материалы (вкл. вспомогательные, энергию и газ на СТН) Затраты на оплату труда

Страховые взносы

Амортизационные отчисления

Прочие, вкл. НДПИ

Услуги сторонних организаций и капремонт

Рис. 1. Структура затрат ООО «Газпром добыча Оренбург» в разрезе секторов деятельности и элементов затрат подразделений на 01.01.2017

В структуре совокупных затрат ООО «Газпром добыча Оренбург» доля материальных затрат составила на 1 января 2017 г. 57,55\%, среди которых наиболее весомыми являются: сырые нефть и газ, газ на СТН - 14,9\%; расходы на электроэнергию - 15,8\%; тепловая энергия - 62,7\% (рис. 2). 
Материальные затраты в целом по ООО "ГДО" на 01.01.17 составили 38443 тыс. р., или 57,55\% в общем объеме затрат

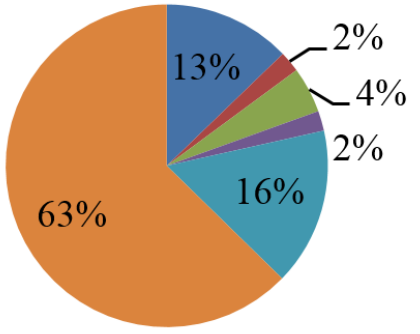

\author{
п сырые нефть и газ \\ газ на СТH \\ вспомогательные материалы \\ п запчасти \\ п электроэнергия \\ - теплоэнергия
}

Рис. 2. Структура материальных затрат ООО «Газпром добыча Оренбург»

Так как энергозатраты доминируют в структуре материальных затратах Общества, далее, с целью выбора наиболее первоочередных направлений инноваций с точки зрения влияния их на снижение себестоимости, было изучено потребление энергоресурсов в целом по Обществу (табл.1) и в разрезе производственных процессов (табл. 2).

Таблица 1

Потребление энергоресурсов ООО «Газпром добыча Оренбург»

\begin{tabular}{|l|c|c|c|c|c|c|c|}
\hline \multirow{2}{*}{ Энергоресурс } & \multirow{2}{*}{ Ед. изм. } & 2014 & 2015 & \multicolumn{2}{|c|}{2016} & \multicolumn{2}{|c|}{$\begin{array}{c}\text { Отклонение } \\
2016 \text { г. к } \\
2015 \text { г. }\end{array}$} \\
\cline { 5 - 9 } Газ на СТН & млн м & 553,1 & 559,9 & 602,3 & 546,5 & $-13,3$ & $-2,3$ \\
\cline { 2 - 8 } & млн p. & 1064,3 & 1209,0 & 1512,8 & 1252,9 & 43,9 & 3,6 \\
\hline \multirow{2}{*}{$\begin{array}{l}\text { Электрическая } \\
\text { энергия }\end{array}$} & $\begin{array}{c}\text { млн } \\
\text { кВт·ч }\end{array}$ & 2133,2 & 2158,6 & 2174,3 & 2159,2 & 0,6 & 0,03 \\
\cline { 2 - 8 } & млн р. & 5838,5 & 6102,8 & 6566,5 & 6547,8 & 445,0 & 7,3 \\
\hline \multirow{2}{*}{$\begin{array}{l}\text { Тепловая } \\
\text { энергия }\end{array}$} & $\begin{array}{c}\text { тыс. } \\
\text { Гкал }\end{array}$ & 5530,1 & 5540,4 & 5477,8 & 5474,5 & $-65,9$ & $-1,2$ \\
\cline { 2 - 8 } & млн р. & 5502,4 & 5513,7 & 6601,8 & 5632,9 & 119,2 & 2,2 \\
\hline
\end{tabular}

Как видим, количество потребленных энергоресурсов за последний год практически не изменилось (при снижении объемов добычи природного газа на 13,6\%). Рост цены покупки газа 1 июля 2016 г. с 1814,00 до 2206,47 руб./тыс.м ${ }^{3}$ (в соответствии с поручением А. Б. Миллера № 01-3608 от 27 сентября 2016 г.) стал причиной роста затрат газа на собственные технологические нужды (3,6\%), а увеличение средневзвешенного тарифа на теплоэнергию с 1205 до 1214 руб./Гкал. привело в росту затрат (2,2\%) при фактическом снижении потребления $(1,2 \%)$. Существенное влияние на рост себестоимости продукции общества оказал рост тарифов на электроэнергию (увеличение затрат на 7,3\% при физическом росте потребления - 0,03\%). При том, что 
О. В. Еременко. К вопросу об эффективности инноваций в отдельных секторах деятельности нефтегазодобывающих предприятий

сокращение объемов добычи произошло более быстрыми темпами, чем физическое изменение затрат, удельный расход их возрос на $6,8 \%$.

Электропотребление общества сохраняется приблизительно на одном уровне. Незначительное увеличение объемов (на $3,1 \%$, или 0,67 млн кВт·ч.) вызвано необходимостью роста степени сжатия ДКС при снижении пластового давления в продуктивных залежах месторождения. В связи с этим увеличиваются часы работы ЭГПА, а также дополнительное включение резервных ЭГПА.

Таблица 2

Структура потребления энергоресурсов в ООО «Газпром добыча Оренбург»

\begin{tabular}{|c|c|c|c|c|c|}
\hline $\begin{array}{c}\text { Сектор / } \\
\text { вид энергии }\end{array}$ & $\begin{array}{l}\text { Ед. } \\
\text { изм. }\end{array}$ & 2015 & 2016 & $\begin{array}{c}\text { Откл. } \\
2016 \text { г. к } \\
2015 \text { г. }\end{array}$ & Причины отклонений \\
\hline \multicolumn{6}{|c|}{ Добыча УВС (ГПУ) } \\
\hline Газ на СТН & тыс. p. & 1054224 & 1053819 & -405 & $\begin{array}{l}\text { Общее снижение затрат } \\
\text { за счет уменьшения объ- } \\
\text { ема потребления газа на } \\
\text { СТН в } 2016 \text { г. на } 452226 \\
\text { тыс. м }{ }^{3} \text { на фазе падения } \\
\text { добычи при незначи- } \\
\text { тельном росте потерь } \\
\text { газа на } 2504 \text { тыс. р., что } \\
\text { связано с принятой схе- } \\
\text { мой разработки место- } \\
\text { рождения. }\end{array}$ \\
\hline Электроэнергия & тыс. p. & 832694 & 906534 & 73841 & $\begin{array}{l}\text { Рост тарифов с } 3,34 \text { p./ } \\
\text { кВт·ч. в } 2015 \text { г. до } 3,66 \\
\text { р./ кВт·ч. в } 2016 \text { г. }\end{array}$ \\
\hline $\begin{array}{l}\text { Тепловая } \\
\text { энергия }\end{array}$ & тыс. p. & 532174 & 543322 & 11158 & $\begin{array}{l}\text { Увеличение затрат в свя- } \\
\text { зи с ростом тарифа в } \\
2016 \text { г. на } 10 \% \text {. }\end{array}$ \\
\hline \multicolumn{6}{|c|}{ Переработка УВС (ГПЗ и ГЗ) } \\
\hline Газ на СТН & тыс. p. & 141618 & 184209 & 42591 & $\begin{array}{l}\text { Увеличение объемов } \\
\text { потребления при изме- } \\
\text { нении структуры перера- } \\
\text { батываемого газа, росте } \\
\text { доли карачаганакского } \\
\text { сырья (затраты возросли } \\
\text { на } 17005 \text { тыс. р.). Рост } \\
\text { тарифов привел к увели- } \\
\text { чению затрат на } 25586 \\
\text { тыс. р. }\end{array}$ \\
\hline Электроэнергия & тыс. p. & 5169948 & 5250553 & 80605 & $\begin{array}{l}\text { Затраты увеличились за } \\
\text { счет роста тарифа на } 6 \% \\
\text { за год }\end{array}$ \\
\hline
\end{tabular}




\begin{tabular}{|c|c|c|c|c|c|}
\hline $\begin{array}{l}\text { Тепловая } \\
\text { энергия }\end{array}$ & тыс. p. & 4974422 & 5081875 & 107453 & $\begin{array}{l}\text { Увеличение тарифов на } \\
10 \% \text { (рост затрат - } \\
81877 \text { тыс. р.) при по- } \\
\text { вышении объемов по- } \\
\text { требления на } 3 \% \text { (затра- } \\
\text { ты возросли на } 25576 \\
\text { тыс. р.) }\end{array}$ \\
\hline \multicolumn{6}{|c|}{ Транспортировка УВС (УЭСП) } \\
\hline Газ на СТН & тыс. p. & 13158 & 14872 & 1714 & $\begin{array}{l}\text { Увеличение объемов на } \\
9,1 \% \text { (затраты возросли } \\
\text { на } 1198,3 \text { тыс. р.) и рост } \\
\text { цены газа на СТН на } \\
3,9 \% \text { (затраты возросли } \\
\text { на 515,5 тыс. р.) }\end{array}$ \\
\hline Электроэнергия & тыс. p. & 26596 & 28858 & 2262 & $\begin{array}{l}\text { За счет увеличения та- } \\
\text { рифов на } 6 \% \text { затраты } \\
\text { возросли на } 1646 \text { тыс. p., } \\
\text { a за счет повышения } \\
\text { объемов на } 2 \%-616 \\
\text { тыс. p. }\end{array}$ \\
\hline $\begin{array}{l}\text { Тепловая } \\
\text { энергия }\end{array}$ & тыс. p. & 7303 & 7703 & 400 & $\begin{array}{l}\text { Увеличение тарифов на } \\
10 \% \text { (затраты возросли } \\
\text { на } 714 \text { тыс. р.) при сни- } \\
\text { жении объемов на } 4 \% \\
\text { (затраты уменьшились на } \\
314 \text { тыс. р.) }\end{array}$ \\
\hline
\end{tabular}

Лидирует по потреблению электроэнергии Гелиевый завод (1 099 млн кВт·ч., или $50,9 \%)$, на втором месте - газоперерабатывающий завод (784 млн кВт·ч., или 36,3\%) [3]. Доля газопромыслового управления (сектор добычи) составила 12,5\% (269,8 млн кВт·ч.).

Всего в 2016 г. потреблено электроэнергии 2 159,2 млн кВт·ч.

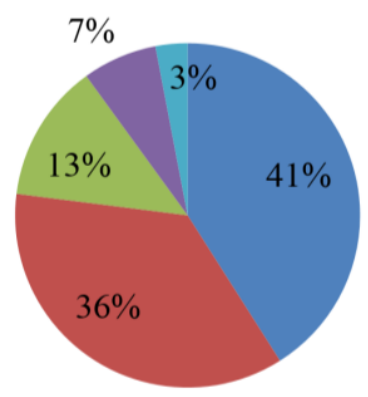

п Гелиевый завод (переработка УВС)

— Газоперерабатывающий завод (переработка УВС)

Шазопромысловое управление (добыча)

घ Управление эксплуатации соединительных продуктопроводов (транспортировка)

Прочие (УАВР, УЭЗиС, УМТСиК и др.) - услуги собственного производства

Рис. 3. Структура физического потребления электроэнергии в разрезе секторов деятельности ООО «Газпром добыча Оренбург» 
О. В. Еременко. К вопросу об эффективности инноваций в отдельных секторах деятельности нефтегазодобывающих предприятий

Потребление обществом тепловой энергии имеет тенденцию к снижению. Главными потребителями являются газоперерабатывающий $(87,3 \%$, или 4622 млн Гкал) и гелиевый заводы (9,2\%, или 489 тыс. Гкал) - сектор переработки УВС. Доля сектора добычи УВС составила 2,5\% (130 тыс. Гкал), транспортировки - 0,2\% (11 тыс. Гкал), услуг - 0,76\% (40 тыс. Гкал) (рис. 4).

\title{
Всегоза 2016 год потребление тепловой энергии составило 5474,5 тыс. Гкал.
}

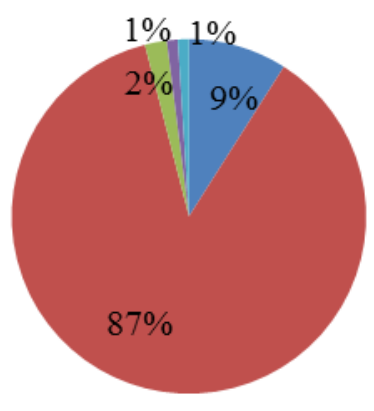

\author{
ш Гелиевый завод (переработка УВС) \\ п Газоперерабатывающий завод (переработка УВС) \\ Газопромысловое управление (добыча) \\ - Управление эксплуатации соединительных \\ продуктопроводов (транспортировка) \\ Прочие (УАВР, УЭЗиС, УМТСиК идр.) - услуги \\ собственного производства
}

Рис. 4. Структура физического потребления тепловой энергии в ООО «Газпром добыча Оренбург»

Таким образом установлено, что прежде всего инновации должны быть направлены:

- в секторе добычи - на оптимизацию и повышение надежности снабжения газопромыслового управления электроэнергией; увеличение выработки собственной теплоэнергии [1;7];

- в секторе переработки - замену списанного, но используемого энергетического оборудования на более технологичное (статоры главных электродвигателей ГПА, комплекты автоматических выключателей, аппараты для высоковольтных испытаний и т. д.); реконструкцию оборудования с целью снижения удельного расхода энергии $[5 ; 14]$;

- в секторе транспорта - на модернизацию оборудования компрессорных цехов для снижения расхода природного газа на СТН [8; 11].

Во всех секторах деятельности предприятия необходимыми являются организационные инновации, направленные на оптимизацию инструментов планирования суточного расхода электроэнергии и поиск оптимального партнера по поставкам электричества на промышленные объекты [12]. Дело в том, что продажу электрической энергии обществу осуществляет ОАО «Межрегионэнергосбыт+», которое закупает электрическую энергию на оптовом рынке. При этом цена кВт·ч. складывается из сбытовой надбавки; стоимости услуг гарантирующего поставщика, коммерческого оператора (ОАО АТC), услуг по оперативно-диспетчерскому управлению (ОАО СО ЕЭС) и комплексных услуг центра финансовых расчетов (ОАО ЦФР). Рас- 
считанная таким образом цена изменяется при отклонении фактического потребления энергии субъектом от заявленных показателей.

Согласно правилам работы рынка электроэнергии, каждому субъекту необходимо обеспечить краткосрочный прогноз электропотребления (почасовое планирование на сутки вперед). При несовпадении плановых и фактических объемов потребления электроэнергии покупатель приобретает объем электроэнергии (мощности) по ценам, рассчитанным с применением утвержденных повышающих коэффициентов (устанавливающихся федеральным органом исполнительной власти в области регулирования тарифов) к средней стоимости единицы с использованием системы коэффициентов, образующих прогрессивную шкалу (отклонения менее $2 \%$ от заявки тарифицируются с коэффициентом 1,0$)$. Таким образом, в целях уменьшения стоимости потребленной электроэнергии при почасовом планировании необходимо учитывать фактическое время работы электропотребляющего технологического оборудования, а в последующем строго соблюдать запланированный режим его работы.

Проблема заключается еще и в том, что договор электроснабжения предусматривает поставку электрической энергии во все секторы деятельности нефтегазодобывающего предприятия как на единый объект, следовательно, графики потребления электроэнергии на сутки вперед всех подразделений складываются и общий график. Хотя в большинстве случаев отклонения фактического потребления составляют менее $2 \%$ (за исключением случаев внепланового вывода (ввода) технологического оборудования из работы (в работу)), тем не менее трудно возложить ответственность за несовершенное планирование на конкретный сектор (подразделение) предприятия.

Обозначенный круг проблем позволил сфокусировать усилия на формулировке приоритетных с точки зрения снижения затрат предприятия инновациях. Среди технологически возможных решений были отобраны наиболее эффективные нововведения и сформирована Программа энергосберегающих и энергоэффективных инноваций ООО «Газпром добыча Оренбург»:

1 Сектор добычи нефти, газа и конденсата:

- замена котельных УКПГ-12,15 на водогрейные котельные автоматизированные транспортабельные КАТ-ЗГ-ГВС (экономия газа на СТН - 49 тыс. м³); замена газовой горелки ГМГ-4м котлов котельных УКПГ на горелку Weishaupt (экономия 191 тыс. м газа и 26,7 тыс. кВт·ч электроэнергии); реконструкция эжекторных установок на ДКС-2 (экономия 3,859 тыс. м³); изменение технологии опорожнения технологических трубопроводов модульной обвязки ГПА, станционных трубопроводов и оборудования с использованием эжекторов на ДКС (экономия 218 тыс. м газа); применение механизированного способа удаления с забоя скважины № 102 скапливающихся жидкостных пробок для исключения продувок газа на амбар (экономия 1,095 тыс. м ${ }^{3}$ газа); замена ламп накаливания 60 и 100 Вт на энергосберегающие мощностью 11 и 23 Вт и установка интеллектуальных датчиков освещения (экономия 627 тыс. кВт•ч).

Реализация комплекса предложенных нововведений позволит сэкономить 6 392,634 т.у.т. на общую сумму 111807 тыс. р. При плановой величине за- 
О. В. Еременко. К вопросу об эффективности инноваций в отдельных секторах деятельности нефтегазодобывающих предприятий

трат в 2018 г. на производство продукции в размере 23882446 тыс. р. снижение совокупных затрат составит $0,47 \%$, а удельных $-0,44 \%$. В целом себестоимость снизится с 1797 до 1789 руб./тыс. м³.

2 Сектор переработки углеводородного сырья:

- оптимизация электропотребления за счет вывода в резерв блока получения ШФЛУ газоперерабатывающего завода (экономия электроэнергии в объеме 1778 тыс. кВт·ч. на сумму 5417 тыс. р.); подача газа на ДКС-2 через резервный коллектор при постановке установок сероочистки ГПЗ на ремонт (снижение расхода топливного газа на собственные нужды $\left(1,8\right.$ млн м $\left.{ }^{3}\right)$ на сумму 3204 тыс. р.); корректировка газодинамического режима работы факельной системы 2-й очереди гелиевого завода с целью сокращения объемов подачи продувочного газа (уменьшение расхода топливного газа на СТН на 3,6 млн м 3 стоимостью 8215 тыс. р.); обустройство ступенчатого сброса давления газа при подготовке к ремонту отделений 202 (У-1), 630 (У-31/32) на компрессоры среднего и низкого давления вместо сброса его на факел ГЗ (экономия газа на СТH - 781 тыс. м $^{3}$, или 2379 тыс. р.): организация процесса подготовки компрессорного оборудования баз 6М25, 6МГМ25 к проведению ремонтов без вскрытия газовой полости ГЗ (экономия 402 тыс. м ${ }^{3}$ газа стоимостью 1225 тыс. р.) и т. д.

В целом снижение расходов на энергоресурсы составит по сектору переработки - 284407 тыс. р., или $1,1 \%$ от совокупных затрат заводов.

3 Сектор транспортировки нефти, газа и газопродуктов:

-замена газовых горелок водогрейных котлов на горелки меньшей мощности (экономия 87 тыс. м $^{3}$ природного газа); введение в эксплуатацию приспособления для розжига и поддержания горения на продувочных свечах очищенного и неочищенного газов (экономия 657,15 тыс. м газа, или 9,13\% от всего объема потребления газа на $\mathrm{CTH}$ ); замена трансформатора ТM2500/10/6 кВ на трансформатор ТСЗЛ-400/10/6 кВ станции «Резервная» (экономия 36,8 тыс. кВтч.); замена сетевого насоса котельной базы на насос с электродвигателем меньшей мощности (экономия 56,2 тыс. кВтч.); установка автоматизированного теплового пункта «Взлет» в здании администрации УЭСП (экономия 132 Гкал). Общая экономия составит 114 т.у.т., или 1 993,87 тыс. p. (0,05\% от совокупных затрат).

Таким образом, сформулированный портфель технологических инноваций для добычи, переработки и транспорта позволит уменьшить совокупные затраты общества до 62 056,5 млн р. в 2018 г., что ниже плановых показателей на 309,8 млн р. В других секторах деятельности затраты снизятся на 15,1 млн р. Себестоимость добычи газа снизится на 7,42 p./тыс. м ${ }^{3}$, себестоимость переработки - 1,46 p./тыс. м ${ }^{3}$, себестоимость услуг по транспортировке

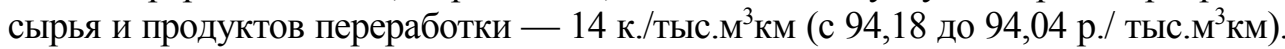
Казалось бы, такие невысокие показатели сокращения удельных затрат не позволяют утверждать, что эти новшества имеют первостепенное значение для нефтегазодобывающего предприятия, однако невысокие инвестиционные затраты, быстрые сроки окупаемости и низкий уровень рисков еще раз убеждают в целесообразности энергосберегающих инноваций. 
Лuтература

1. Ивановский В. Н. Энергетика добычи нефти: основные направления оптимизации энергопотребления / В. Н. Ивановский // Инженерная практика. 2011. № 6. С. 18-26.

2. Еременко О. В. Макроэкономические аспекты необходимости перехода к инновационно-ориентированной модели управления нефтегазовым комплексом России в условиях формирования глобального газового рынка / О. В. Еременко // Конкурентоспособность в глобальном мире: экономика, наука, технологии. 2017. Ч. 3, № 4. C. $73-77$.

3. Еременко О. В. Организационно-экономический механизм реализации инноваций в рамках энергоменеджмента газоперерабатывающего завода [Электронный ресурс] / О. В. Еременко // Управление экономическими системами: электронный научный журнал. 2017. № 4(98). C. 14-24. URL: http://uecs.ru (дата обращения: 10.12.2017).

4. Еременко О. В. Особенности определения ставки дисконтирования при оценке эффективности инновационных проектов в сфере разработки и эксплуатации месторождений нефти и газа. Общеметодологические проблемы / О. В. Еременко // Актуальные проблемы экономики и управления. 2017. № 1. С. 46-56.

5. Еременко О. В. Приоритеты инновационного развития и особенности оценки эффективности проектов в газоперерабатывающих и газохимических производствах: учебное пособие / О. В. Еременко. Москва ; Берлин: Директ-Медиа, 2017. 171 с.

6. Еременко О. В. Методические особенности определения эффективности инновационных проектов в сегментах деятельности нефтегазодобывающих компаний при изменении уровня риска / О. В. Еременко // Наука сегодня: постулаты прошлого и современные теории : материалы VIII Международной научно-практической конференции / отв. ред. А. А. Зарайский. Саратов : Академия Бизнеса, 2017. С. 72-76.

7. Карасева Е. В. Анализ возможных схем энергообеспечения нефтегазовых промыслов с учетом фактора надежности / Е. В. Карасева // Экономика и предпринимательство. 2015. Ч. 2, № 11. С. 880-884.

8. Новак А. В. Основные направления повышения энергоэффективности и развития энергетики [Электронный ресурс] / A. В. Новак. URL: http://federalbook.ru (дата обращения: 10.12.2017).

9. Новикова А. С. Оптимизация методов управления ресурсами УВС для обеспечения роста инновационного потенциала нефтегазового бизнеса России / А. С. Новикова, О. В. Еременко // Общество в эпоху перемен: формирование новых социальноэкономических отношений : материалы международной научно-практической конференции / отв. ред. А. А. Зарайский. Саратов, 2017. С. 77-79.

10. Новикова А. С. Инновационные подходы в формировании комплекса мероприятий по ресурсосбережению в нефтегазовых компаниях / А. С. Новикова, О. В. Еременко // Экологическая ответственность нефтегазовых предприятий : материалы научно-практической конференции / под общ. ред. С. Г. Горшенина. Москва ; Оренбург, 2017. С. 214-218.

11. Обзор передового отечественного и зарубежного опыта в области энергосбережения повышения энергетической эффективности : сборник материалов. Москва, $2014.158 \mathrm{c}$.

12. Повышение энергоэффективности как драйвер роста и инструмент модернизации экономики России // Энергоэффективность и энергосбережение : материалы II Международного форума [Электронный ресурc]. URL: http://enesexpo.com/docs/prezentatsii_dlya_programmy/21112014/Minenergopdf (дата обращения: 10.12.2017).

13. Шпаков В. А. Особенности управления качеством инновационного потенциала и инновационной активностью нефтегазодобывающих компаний России. Ч. 2. 
О. В. Еременко. К вопросу об эффективности инноваций в отдельных секторах деятельности нефтегазодобывающих предприятий

Корпоративные и региональные аспекты / В. А. Шпаков, О. В. Еременко // Управление качеством в нефтегазовом комплексе. 2017. № 1. С. 26-30.

14. Черномуров Ф. М. Энерго- и ресурсосбережение в нефтегазохимическом комплексе / Ф. М. Черномуров. Екатеринбург : Изд-во УФУ, 2014. 253 с.

\title{
TOWARDS THE EFFECTIVENESS OF INNOVATION IN THE SELECTED SECTORS OF ACTIVITY OF OIL AND GAS PRODUCING ENTERPRISES
}

\author{
Olga V. Eremenko \\ Cand. Sci. (Econ.), \\ Gubkin Russian State University of Oil and Gas, Orenburg Branch \\ 20 Yunikh Lenintsev St., Orenburg 460047, Russia \\ E-mail: overemenko71@mail.ru
}

The deteriorating conditions in the world fossil fuel market, significant depletion of reserves, technical problems encountered in field development and operation, lack of financing sources for rational and conforming to international standards reproduction of capital funds, and increasing computerization of technological processes emerge an objective need for introducing innovations in different spheres of activity of oil and gas producing enterprises. However, the problems of assessing the effectiveness and prioritizing certain innovations come up against a number of peculiarities related not only to the specific oil and gas fields, but also to the sectors of activity of Russian subsoil users. The article consider some of these sectors and the possibility of unifying approaches to assessing innovations in terms of their influence on reduction of production costs. To this end, we have used the methods of grouping and correlationregression analysis in the work. The proposals are formulated and adapted on the example of a particular oil and gas producing enterprise and can be used to assess the effectiveness of energy-saving innovations at field production project sites.

Keywords: innovations of Russian subsoil users; efficiency of resource-saving innovations. 